\title{
Statistics Communication and Tracking Documentation
}

National Cancer Institute

\section{Source}

National Cancer Institute. Statistics Communication and Tracking Documentation. NCI

Thesaurus. Code C115729.

Records pertaining to statistics communication and tracking used in a clinical trial. 